\title{
Exploratory factor structural of environmental perception
}

\begin{abstract}
Studies of risk perception, in relation to the governance of risk events, have advanced towards a management, production and knowledge transfer system focused on the impact of the media on audiences and eventually on the leaders of Civil protection institutions, but the absence of research encouraged the present work to establish the reliability and validity of an instrument. The proposal was based on a non-experimental study and a non-probabilistic sample selection of 100 students from a public university. Based on a structural model, it was found that Internet users perceive risks and affect media perception and perception social on the perception of risk events, although there are lines of research concerning the mediation of such dependency relationships.
\end{abstract}

Keywords: climate change, governance, risk, perception, model
Volume 4 Issue 6 - 2020

\author{
Cruz García Lirios,' José Marcos Bustos \\ Aguayo, ${ }^{2}$ Margarita Jua'rez Nájera, ${ }^{3}$ Francisco \\ Ruben Sandoval Vazquez ${ }^{4}$ \\ 'Department of Social Work, UAEMEX, Mexico \\ ${ }^{2}$ Department of Psychology, UNAM, Mexico \\ ${ }^{3}$ Department of Energy, UAM, Mexico \\ ${ }^{4}$ Department of Political Science, UAEM, Mexico
}

Correspondence: Cruz García Lirios, Department of Social Work, UAEMEX, Mexico, Tel 525525I84238,

Email bundesnanza@yahoo.com

Received: October 17,2020 | Published: November 09, 2020

\section{Introduction}

The process is to ensure that natural disasters and ecological catastrophes far are not linked to the personal situation, or local issues are not of such magnitude involving a conservationist action, is known as an environmental farsightedness. In this sense, this paper aims to specify a model for the study of this perceptual bias that explains the relationship between nature and humanity.

Psychology of Sustainability (PS) has established theoretical and conceptual frameworks to explain the causal relationship between water availability and consumption per capita through cognitive processes. In this sense, the objective of this paper is to present theories about environmental situations. For this purpose, from a review of the state of knowledge causal relationships between hydrological exclusion and culture, the state, society, the media, communities, neighborhoods, families and individuals are explained. Theoretical models for explaining the beliefs, values, perceptions, attitudes, knowledge, motivation, skills, intentions and behaviors in terms of scarcity, shortage and environmental unhealthiness ${ }^{1}$ arise. Exposing the theoretical framework will serve to open the discussion about the accuracy, development, construction and innovation of theoretical models that link personal areas, family, territorial, local, regional and global where water scarcity impacts the behavior human by regulating basic social - cognitive processes.

Situational global water trends are set up to project the corresponding local water sustainability's. In this sense, public policies are essential to establish the costs of water supply. However, civic, community and neighborhood involvement are also critical in establishing water unit prices.

Thus, at the global level, water sustainability is determined by public policies that encourage water conservation through tariff international standards. The price of water would be a result of international conventions to which the signatory countries undertake to reduce their agricultural, industrial and commercial processes. The unit cost would be defined by the level of availability per capita. A greater amount of water for each person involves a standard cost for plaintiff. ${ }^{2}$. Consumption above a threshold exponentially increase the unit price. Globally, costs are reduced, and profits would increase substantially. However, presidents or ministers cannot make global decisions without compromising local development.

In this regard, the continental level, the relationship between the industrial North and the agricultural South, trade between the economic blocs, directly affects the financial and migratory flows that should be considered in the equation of public policy for water sustainability. In the continents, the establishment of a system of charging water service is more likely when considering trade agreements between members of economic blocs. Meanwhile geopolitical group, a public policy-oriented tariffs would benefit from the rich to the livelihoods of poor residents ${ }^{3}$ citizens. This is a tariff system in which those with greater purchasing power pay a standard fee that includes funding for those living in exclusion, marginalization or vulnerability. However, localism still have a specific weight when setting standard rates and, therefore, is required to review the national level to clarify the factors that prevent sustainability at continental level.

One cause of economic blocks has been nationalisms. Since nationalist conflicts that led Europe to create a common market to promote regionalism today the collapse of monarchies in Africa and the Middle East, local ideologies have determined the evolution of societies. In Mexico, conflicts over water rights have been palliated with centralists and federalist's public policies in which the extraction and distribution from one basin to another is warranted. The State, through estimates of the Secretariat of Finance and Public Credit (SHCP), the Bank of Mexico (BM) and the National Water Commission (Conagua) ${ }^{4}$ has established public policies aimed at economic growth rather than development sustainable. The State of water rights and heritage of rural communities and urban neighborhoods. In this regard, each unit of water has a different and inequitable price. Water is cheap for those with greater purchasing power and consume more. Instead the groups that save water, despite being unemployed or underemployed, paid five times their actual cost. However, the national water policy is diversified statewide.

In a federalist country, state governments are a counterweight to the omnipresence of the executive. An initiative of the president can be modified by the Senate and low, the state legislature and the 
governor. If this altitude in rural communities and urban neighborhoods live is added, the states must legislate a system of differential tariffs for each entity. Therefore, the state water sustainability in finance would state their main obstacle. Often, state governments spend more than they receive from the federation. This encourages the national and local utilities seek agreements to build a subsidy system that benefits low prices to users. The result is a public action organized for the collection but disorganized for delivery. Without fail, receipts are distributed to users, but water service is intermittent. Therefore, the state water sustainability benefits the cities to the detriment of rural areas.

It could ensure that since the founding of the Valley of Mexico was an obvious overload. Over the centuries and cultures basin has been emptied. It is estimated that the current trend extraction would reach for two or three decades to compromise its structure. The geographical complexity is not less than the sociopolitical complexity. The Valley of Mexico, managed by three entities with their respective congresses, including a metropolitan water policy which would be defined by representatives of different locations with different needs, expectations and consumption capabilities. However, the Mexican Political System (PMS) is characterized by homogenizing the demands of the people and the corresponding offers. From this structural political trait, a water policy pricing system is actually a system of grants, subsidies and waivers. This is a public policy that does not need to be legislated to be implemented. At election time, the effectiveness of the political system uses to drinking water as their promotional tool definition and selection of candidates and representatives. Thus, the metropolitan water sustainability is discretionary, proselytizing and clientelism. Consequently, a borough level, corruption, nepotism and cronyism are its main components. ${ }^{5}$

One consequence of the complexity of the Valley of Mexico are its borough and municipal demarcations. The diversity of factors influencing the metropolitan water sustainability also affects water sustainability to local level. However, delegations are grouped into two groups: inclusive and exclusive. The first low population density and high income that would allow solve an exponential increase in rates. The latter are overcrowded, unemployment or underemployment with insufficient income to afford a minimum variation of the unit price of water. In the case of Iztapalapa, we should add altitude and corruption in the neighborhoods with greater shortages and unsanitary living. This is a delegation in which several factors converge, and near a water crisis to its people. This situation favors the emergence of location-actions or intentions of discontent, protest or boycott confrontation aimed at obtaining a greater amount of water. Thus, water sustainability in Iztapalapa require tailored to the uses and customs of the people fighting corruption but at the same time accept the patronage rates. In this sense, the styles of family-residential life complement their collective mobilizations.

In the residential area, the water shortage is the main trend would lead to hoarding families, dosage and seudo-reparation leak. Indeed, a system of tight austerity strategies involve thresholds consumption rates determined by the number of residents, their economic activities and types of entertainment. At the level of the family groups-residential water sustainability it means a payment funded to save water and an exponential who squander or hoard the price. Consumer skills and leak seudo-reparation imply a lower subsidy that would conform to a standard price considering the future trend.

Finally, the water project future trends exposed scenarios where urban density is a global, national and local problem affecting water sustainability. That is, the per capita availability expected for the coming years is a result of public policies that seek to curb the trend water to make it more sustainable. In that sense, it is predictable disappearance of standards, subsidized, situational, or thresholds intervals tariff systems. Instead, a new pricing system should be implemented to address the structural flaws. This is a particular system of global water fees to local contingencies. ${ }^{6,7}$

Psychology of Sustainability, farsightedness, in its general conception, is skewed perceptions regarding the impact of environmental catastrophes and natural disasters resulting from climate change which are appreciated by society as isolated events that do not would impact either directly or indirectly in quality life, residential comfort and subjective well - being.

Corral et al. ${ }^{8}$ in the context of the psychology of water resources and services, found that the utilitarian beliefs determine water consumption indicated by washing dishes, grooming, watering plants, washes dishes and cleaning sidewalk. That is, the information concerning droughts, scarcity and shortages seems to influence the beliefs that process information in such a way that water is considered an instrument of cleanliness, comfort and relaxation. Hyperopia appears to be a complex process that would be indicated by their degree of utilitarianism.

Thus, farsightedness precedes utilitarian beliefs, but in relation to processing systems and information categorization suppose, for Corral et al., ${ }^{9}$ other relationships with perceptions of time perspective: 1) orientation to the past, 2) future orientation and 3) sustainable styles with dimensions such as: a) this hedonistic, b) present fatalistic, c) positive last d) past negative e) propensity future. Each of the dimensions, to interact with each other in order to anticipate water conservation, perceptual and behavioral established a system that would be linked with farsightedness past orientation and dimensions of the hedonistic past present and positive. That is, hyperopia would be a process of information concerning past located in the risks that would be little related to this comfort and unlinked future.

However, if farsightedness supposed informational categorizations that will result in the utilitarianism of water resources and services, then the hedonism is not only detached from the perceived risks in the past and would not have a significant impact on the present, but also would you relate to utilitarianism which regards natural resources and public services as instruments of comfort.

Utilitarianism and hedonism, while social norms and values scattered groups consider water as a means of comfort, determine damaging behavior. The study of Frías et al. ${ }^{10}$ shows that social norms determine individual principles crystallized into specific actions, but both are embodied in moral standards define an identity based on the context. That is, hyperopia is also the result of a process of identification of the individual with regard to the conduct of a group and social actions to droughts or floods, which were disseminated in the media and led a hedonistic response rather than conservationist.

Hyperopia would be reflected by utilitarianism and hedonism that the reference group or membership developed and influenced the individual in a hostile environment, although permissible with group's skewed perceptions towards self - management capabilities of natural resources and public services.

However, from the perspective of Gilford, ${ }^{11}$ pessimism rather than fatalism is different spatial levels: local, national and global. Consequently, farsightedness is not just a perceptual bias of social, collective and personal standards indicated by their 
degree of usefulness and hedonism, but also is a bias scenario that the recipient is unknown and homogenized thus to have control or certainty context of water availability.

Farsightedness, as a spatial bias, explain the biophilia in contexts of natural diversity as a determinant of pro - environmental behavior. Corral et al. ${ }^{12}$ modeled both variables with social intolerance and age to show that there was an implicit relationship between environmental conservation and affinity towards nature. In this sense, farsightedness would be linked to social intolerance since the biophilia would immediate and specific conservation actions in the immediate environment, but once guaranteed the existence of species, the individual could develop a hedonism and utilitarianism to its preserved environment. Under its regulations, valuation, perceptual, attitudinal and behavioral implications hyperopia is a complex psychological construct sustainable which is an interdisciplinary study. The implications of the study for hyperopia have environmental policies and public services are unpublished.

In principle, a socio - political farsightedness would be indicated by perceptual biases about the relationship between society, state and nature. In that vein, utilitarianism and hedonism reported in studies of the psychology of sustainability serve to conceptualize the social and political dimension of farsightedness as one in which climate change, resource scarcity and shortages in the cities would be an instrument power and control would reduce civil participation conflicts with their authorities and natural resources in tandem services. Thus, the social and political farsightedness explain social mobilization and collective action such as demonstrations, rallies, sit - ins or marches as instruments of pressure and negotiation between public service users and local authorities.

\section{Environmental perception}

Socio - political farsightedness specification implies the establishment of the effects of ecocentric campaigns in the preservation of the water market. From the sixties, ecological movements that shown the harmful effects of the market economy, liberal policies, industrial societies, the massification of services and consumerism of diversified products..$^{13}$ Later, in the seventies, the anti-armaments movements that are more concerned with the preservation of animal and plant species ${ }^{14}$ species arise.

Conservation demonstrations raised the exploitation of resources based on availability. In the eighties, ideas and environmental actions such as boycotts of products and services, consumption metering and even abstentionism characterize post - industrial societies. Given the uncertainty and insecurity arising from radioactive Chernobyl reactor explosion, environmental groups were organized to protest massively and systematically in major cities worldwide. The fall of the socialist bloc showed new forms of nuclear destruction of the environment and with them, new forms of environmental organization. ${ }^{15}$

Marches, rallies and demonstrations gave way to realistic demonstrations of the extermination of species when dead cetacean's environmental groups moved to the streets of European cities. These demonstrations were complemented by actions of direct intervention to prevent the extermination of whales, seals, bears or birds. Demonstrations leave the streets and enter the portals of government institutions. ${ }^{16}$ Blocking servers and network attack with computer viruses are examples of activism that characterizes the nineties. Finally, the consolidation of sustainable development extended to the economic, political, social, cultural, educational, scientific and technological growth depending on the availability of resources without affecting the ability of future generations to use these resources areas. In this sense, political campaigns have used the principles of sustainable development to attract followers (Vervoort et al., 2014).

In the hydrological context, vows are exchanged for water redistribution. However, sustainable development coexists with another form of hedonistic, improvised and development Heuristic: liquid consumption. ${ }^{17,18}$

The majority influence suggests that the systematic use of a resource is determined by the power of majority decision. If the bulk of the population has a habit of daily grooming, then the individual will be influenced to adopt a style of anthropocentric life where water resources are considered an exclusive service for current human needs, regardless of the capabilities human generations later and the needs of current and future species. ${ }^{19}$ The majoritarian model is straightforward because through considered an expert source may influence the decision of the individual consumer. Indeed, the conformity of the individual is the result of the majority influence. ${ }^{20}$

In contrast, argues that minority influence consumption of natural resources due to the identity established by the individual to the group around him. Thus, grooming can vary depending on the lifestyle of the group to which the individual belongs. If the group has a policy of grooming with a minimum of water, then the individual will perform that action regardless of the availability of water. ${ }^{21}$ This is an indirect influence as lifestyle impacts the future rather than the consumption decision in the present. Therefore, innovation is the main consequence of the minority influence.

Both processes of social, majority or minority influence, seem to ignore the availability of resources that economic approach shows how essential factor, are nevertheless relevant because warn that regardless of the amount of consumable water, decision making present or future is determined by the social norm or the standard group. ${ }^{22}$

Symbols, meanings and senses that correspond are the means involving the prematerialists cultures, cultures and post - materialist materialistic cultures with the environment. ${ }^{23}$ In pre-materialist cultures, nature is symbolized as a conglomeration of such significant community elements such as human elements forming a group. ${ }^{24}$

In contrast, often, nature is symbolized as inexhaustible resources by groups that transform and redistribute promoting inequalities characteristics of neoliberal economic societies. Finally, when the post - materialist cultures have reached a very high economic and educational status, nature is symbolized as a stage for the rights of each agency for its subsistence. ${ }^{25}$ From these cultural distinctions nine theories explain the cultural world views of nature.

The theoretical relations between the perceptual factors are adjusted to the empirical observations in the locality of study, or will they be different given the specificity of the relations between the political and social actors with respect to the environmental perception of the resources and the water services.

The relations between the factors when explained from global and regional references, anticipate local scenarios considering the specificity of the actors regarding the scarcity, shortage, unhealthiness and scarcity of the municipal water service.

Although the asymmetries between governments and citizens are observable in the perceptions about the quality of the water service, local inequalities such as hoarding, conflicts and dosing skills lead to perceptions of risk rather than utility of the municipal service. 


\section{Method}

A non-experimental, cross-sectional, exploratory and correlational study was carried out. 45 students from a public university in central Mexico, considering their experience in environmental risk events such as frosts, floods, landslides, droughts and fires. $48 \%$ are women and the remaining $52 \%$ are men. $61 \%$ are under 18 years old $(\mathrm{M}=$ $17,03 \mathrm{SD}=0,28), 35 \%$ are between 18 and 22 years old $(\mathrm{M}=19,20$ $\mathrm{SD}=0,18)$, the remaining $4 \%$ are older than 22 years $(\mathrm{M}=23.21 \mathrm{SD}$ $=0.16)$.

The Environmental Risk Perception of Carreón (2016) was used, which includes 28 items related to the perception of risk events, setting of the perception of events, social amplification of risk and perception of Internet risk. Each reagent includes five response options ranging from $0=$ not at all likely, $1=$ very unlikely, $2=$ unlikely, $3=$ somewhat likely, 4 = very likely.

The precise purpose of this paper is to specify the construct of social and political farsightedness to delineate their study in a reflective model. For this purpose, a documentary research was conducted in the databases Dialnet, Latindex, Publindex, Redalyc and Scielo. Subsequently, the definitions in a matrix of content analysis were processed and, finally, the indicators taken in reviewing the state of knowledge is modeled. For such purposes, it carried out a study on during the period from 2010 to 2018 in articles with record ISSN and DOI concerning environmental farsightedness. The specified model includes eight dimensions alluding to perceptual bias with respect to supply local and residential water. Referring to the state of knowledge, the specification was proven in order to anticipate scenarios analysis, perceptual structures, decision-making and behavior depending on water availability and needs / expectations of local consumption.

The Delphi technique was used for the processing of information, comparing and integrating data according to the dimensions established in the theory. Students were surveyed in the vestibule of their university with a written guarantee of confidentiality and anonymity of their answers, as well as a warning that the results of the study would not negatively or negatively affect their economic, political and social status.

Crombach's alpha was estimated to establish the consistency of the scale, adequacy, sphericity and validity of the scale to demonstrate the convergence of constructs from the indicators, correlations and regressions to demonstrate the dependency relationships among the variables, adjustment statistics and residual to test the null hypothesis.

The information was processed in the Statistical Package for Social Sciences and the Structural Moments Analysis software version 5.0

\section{Results}

Table 1 shows the internal consistency values for the general scale (alpha of 0,777) and the subscales (alpha of 0,781; MAR alpha of 0,785 ; SAR alpha of 0,792 and IPR alpha of 0,782 ), which exceeded the minimum required of 0.700 but lower than an optimum consistency of 0.800 .

Table 2 and Figure 1 shows the incidence of Internet user perception of risks on the medialization of risk perception, as well as the influence of the social amplification of risk on the perception of risk events. That the hypothesis of the rector of the State prevails but bounded by the hypothesis of community resilience. Both point out that there are differences between governors and the governed, but it is the rectory of the State that propitiates the phenomenon of risk events, even though civil society contributes in a determined manner so that the information is amplified through traditional means and electronic.

Table I Descriptive of the instrument

\begin{tabular}{|c|c|c|c|c|c|c|c|}
\hline $\mathbf{R}$ & $M$ & $\mathbf{S}$ & A & FI & F2 & F3 & F4 \\
\hline$r I$ & 1,23 & 0,10 & 0,781 & & & & 0,303 \\
\hline r2 & $\mathrm{I}, 42$ & 0,12 & 0,793 & & & & 0,384 \\
\hline r3 & 1,53 & 0,18 & 0,742 & & & & 0,395 \\
\hline r4 & 1,50 & 0,32 & 0,743 & & & & 0,384 \\
\hline r5 & 1,03 & 0,82 & 0,783 & & & & 0,381 \\
\hline r6 & 1,25 & 0,25 & 0,773 & & & & 0,306 \\
\hline r7 & 1,36 & 0,35 & 0,781 & & & & 0,394 \\
\hline r8 & 1,46 & 0,31 & 0,702 & & & 0,394 & \\
\hline r9 & 1,92 & 0,93 & 0,721 & & & 0,362 & \\
\hline rlo & $\mathrm{I}, 47$ & 0,92 & 0,731 & & & 0,315 & \\
\hline rll & $I, I I$ & 0,04 & 0,742 & & & 0,368 & \\
\hline $\mathrm{rl} 2$ & 1,05 & 0,72 & 0,704 & & & 0,345 & \\
\hline $\mathrm{r} / 3$ & 1,25 & 0,15 & 0,705 & & & 0,395 & \\
\hline $\mathrm{rl} 4$ & 1,05 & 0,35 & 0,77 I & & & 0,386 & \\
\hline rl5 & $|, 0|$ & 0,24 & 0,782 & & 0,306 & & \\
\hline $\mathrm{rl} 6$ & 1,16 & 0,36 & 0,794 & & 0,315 & & \\
\hline rl7 & $|, 2|$ & 0,27 & 0,705 & & 0,306 & & \\
\hline rl8 & $\mathrm{I}, 07$ & 0,35 & 0,782 & & 0,391 & & \\
\hline$r 19$ & 1,02 & 0,46 & 0,77 I & & 0,306 & & \\
\hline$r 20$ & $\mathrm{I}, 14$ & 0,37 & 0,776 & & 0305 & & \\
\hline r2I & $\mathrm{I}, 15$ & 0,83 & 0,766 & & 0,384 & & \\
\hline r22 & 1,26 & 0,30 & 0,785 & 0,385 & & & \\
\hline r23 & 1,26 & 0,49 & $0,76 I$ & 0,306 & & & \\
\hline r24 & 1,03 & 0,27 & 0,732 & 0,340 & & & \\
\hline r25 & 1,12 & 0,13 & 0,745 & 0,381 & & & \\
\hline r26 & 1,16 & 0,25 & 0,723 & 0,305 & & & \\
\hline r27 & $|, 2|$ & 0,15 & 0,752 & 0,306 & & & \\
\hline r28 & 1,47 & 0,12 & 0,751 & 0,351 & & & \\
\hline
\end{tabular}

Source: Elaborated with study data; R, reactive; M, median; SD, standard deviation; $A$, alpha by removing the value of the item. Extraction method: main axes, promax rotation. Adequacy and Sphericity $\left\lceil X^{2}=432,46(46 \mathrm{gl}) \mathrm{p}=0,000\right.$; $\mathrm{KMO}=0,67 \mathrm{I} \mathrm{J} . \mathrm{FI}$, perception of risk events (alpha of $0,78 \mathrm{I}$ and $24 \%$ of the variance explained); F2, media amplification of risk (alpha of 0,785 and $18 \%$ of the variance explained); F3, social amplification of risk (alpha of 0,792 and $14 \%$ of the variance explained); F4, internet risk perception (alpha of 0,782 and $6 \%$ of the variance explained). Each reagent includes five response options ranging from $0=$ not at all likely, I = very unlikely, 2 = unlikely, 3 = somewhat likely, 4 = very likely.

Table 2 Correlations and covariations

\begin{tabular}{lllllllll}
\hline & FI & F2 & F3 & F4 & F I & F2 & F3 & F4 \\
\hline FI & $\mathrm{I}, 00$ &, $325^{*}$ &, $432^{*}$ &, $435^{* *}$ & $\mathrm{I}, 98 \mathrm{I}$ &, 324 &, 345 &, $43 \mathrm{I}$ \\
\hline F2 & & $\mathrm{I}, 00$ &, $346^{*}$ &, $432^{* * *}$ & & $\mathrm{I}, 876$ &, 435 &, 329 \\
\hline F3 & & $\mathrm{I}, 00$ &, $32 \mathrm{I}^{*}$ & & & $\mathrm{I}, 897$ &, 436 \\
\hline F4 & & & $\mathrm{I}, 00$ & & & & $\mathrm{I}, 456$ \\
\hline
\end{tabular}

Soured: Elaborated with data study; FI, perception of risk events; F2, media amplification of risk; $\mathrm{F} 3$, social amplification of risk, $\mathrm{F} 4$, internet risk perception: $* \mathrm{p}<, 01 ; * * \mathrm{p}<, 00 \mathrm{I} ; *^{* *} \mathrm{p}<, 000 \mathrm{I}$. 


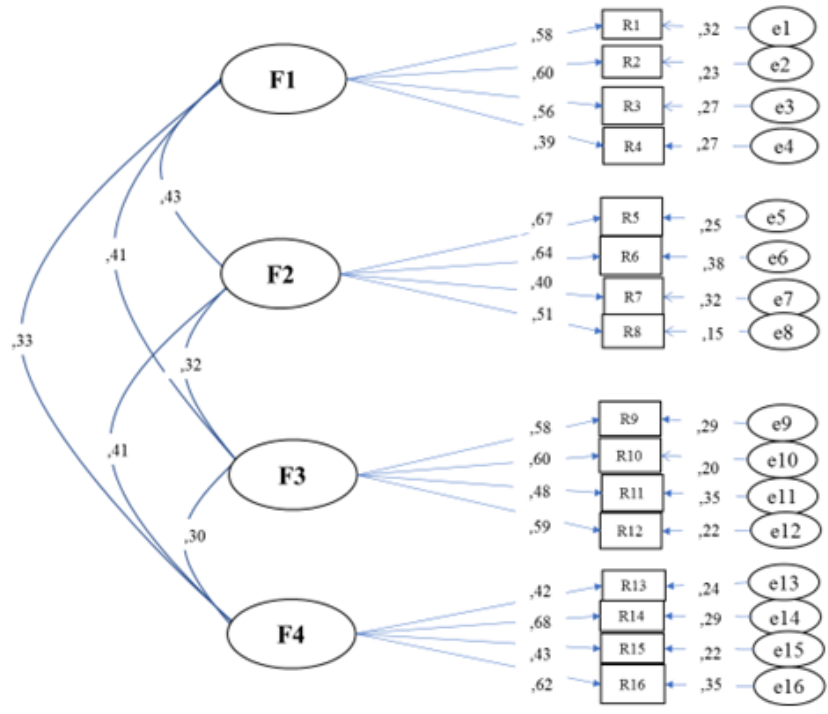

Figure I Model to environmental risk perception.

Source: Elaboration with study data; FI, perception of risk events; F2, media amplification of risk; $F 3$, social amplification of risk; $F 4$, internet risk perception: $\cap$ relations between factors, $\leftarrow$ relations between errors and indicators; $\rightarrow$ relations between factors and indicators.

The adjustment and residual parameters $\int \mathrm{X}^{2}=234,13(35 \mathrm{gl}) \mathrm{p}=$ 0,012; CFI $=0,990 ; \mathrm{GFI}=0,995 ; \mathrm{IFI}=0,975 ; \mathrm{RMSEA}=0,009]$ show that the null hypothesis can be accepted since, the theoretical relationships seem to fit the data observed in the context and the study sample.

\section{Discussion and conclusion}

The contribution of this study to the status of the issue lies in the establishment of the reliability and validity of an instrument that measures perceptions around risk events such as hurricanes, floods, mudslides, droughts, frosts or fires, but the type of study, the type of sample selection and the type of analysis limit the results to the study sample and the research context.

It is recommended to study the dimensions of social risk amplification and the perception of risk in order to establish the factors that mediate the relationship with the medialization of risk events and the perception of them.

The dimensions involved with hyperopia derived from the natureculture, resources-State-payers, product-market-consumers, and spots -Means-viewer's and-stakes situations. They have been exposed to explain environmental dimensions from its relations with situations culture, society, the state, the community, the neighborhood, the family and the individual. In this sense, environmental situations are conceptually derived from entities from which you can see them, compare, analyze and synthesize. When mankind felt that the water and she were part of nature, transformed into symbols that cultures emerged. When humanity classified as water resources, it unveiled the State which became taxpayers. When humanity thought the water was a product created the market that turned into consumers. When humanity reduced to spots environmental situations, he extolled the media that turned into spectators; and when humanity realized the diversity of environmental situations, he outorganize to preserve future generations.
The relationships between the availability and consumption by socio-cognitive processes underlying environmental media hypothesis around which the amount of water and the use thereof are determined by preliminary ideas to be processed in situations of abundance or scarcity inhibit or will facilitate the waste or water savings regardless of value, cost, price, rate, quote or any other parameter that involves restoring balance in the availability and consumption.

However, it is necessary to reconceptualize the problem and establishing cost parameters from human needs and expectations regardless of their abilities or property. In this sense, the sociopsychological theories propose that measurement of water consumption is carried out, and not according to their current or future availability, but in terms of beliefs, perceptions, attitudes, knowledge, values and intentions of use inserts water supply system in individuals. That is, the socio-psychological theories only explain the sustainability of a formal market supply, but referring to an informal market, theories are barriers to explain the solidarity shortages or hoarding situations abundance.

Therefore, the socio-psychological theories have to explain discrepancies that inhibit sustainable development of mankind in relation to water availability. In this regard, the socio-psychological theories should be complemented by other theories to explain the emotions rather than rationality around the use of water, the groups to which the user belongs, quotation systems in which the user is assigned or governance processes in which citizens participate.

The perception of risk events is an essential process in the explanation of the differences between governors and the governed with respect to levels of territorial, national, public, civil, human, private or Internet security. It is a phenomenon in which, although risk events are impenetrable and incommensurable, the information disseminated in favor of the rector of the State legitimizes their power and the information related to civil resilience legitimizes their defenselessness. In the construction of a governance of risks and security it is necessary to dismember both processes in order to move towards a common future in terms of managing risks.

\section{Acknowledgments}

None.

\section{Conflicts of interests}

The authors declare no conflict of interests.

\section{References}

1. Tronu G. General environmental attitudes and beliefs: the spatial bias and the NHIP scale. Tesi di Dottorato. Universita di Roma. 2011.

2. Uzzel D. The psychospatial dimension or $\mathrm{n}$ of a global environmental problem. Journal of Environmental Psychology. 2000;20:307-318.

3. Uzzel D. From Global to Local. A case of environmental hyperopia. International Human Dimensions Programme on Global Environmental Change. 2004;4:6-9.

4. Commission or National Water. water banks in Mé Mexico. M é Mexico Conagua. 2012

5. National Institute Statistical Geography \& Informatic. Women and men in Mé Mexico. M é Mexico: INEGI. 2010.

6. United Nations Habitat. Sick water? The role of the central wastewater management in sustainable. A rapid response assessment. Birkiland: Author. 2010. 
7. United Nations Water. Water \& the overall water security agenda. Ontario: United Nations University. 2013.

8. Corral V, Fraijo, Tapia BC. An observational record of individual consumption of water; applications for research or $\mathrm{n}$ of sustainable behavior. Revista Mexicana de A to lysis of Behavior. 2008;34(1):79-96.

9. Corral V, Fraijo B, Pinheiro J. Sustainable behavior and time perspective: present, past, and future orientation and Their relationships with water conservation behavior. American Journal of Psychology. 2006;40(2):139-147.

10. Fríace M, Rodríguez A, Corral V. A to analysis of factors influencing the development of environmental standards and the behavior. Interamerican Journal of Psychology. 2009;43(2):309-322.

11. Gilford R. Temporal and spatial optimism pessimism in environmental assessment. Journal of Environmental Psychology. 2009;29:1-12.

12. Corral V, Bonnes M, Tapia C, et al. Correlates of pro-sustainable orientation the affinity towards diversity. Journal of Environmental Psychology, 2009;29:34-43.

13. Amérigo M, Aragonés J, Sevillano V, et al. The structure of beliefs about the problem to environmental policy. Psicothema. 2005;17(2):257-262.

14. Larson K, White D, Gober P, et al. Divergent perspectives on water resource sustainability science in a public policy context. Environmental Science \& Policy. 2009;12:1012-1023.

15. Lucio H, Pinheiro J. Dimension is ecological requirement overall under vis ã or brasileiros adolescents. Estudos Psychology. 2013;18(2):173-182.

16. Milfont T, Sibley C, Duckitt J. Testing the moderating role of the components of norm activation on the relationship Between values and environmental behavior. Journal of Cross-Cultural Psychology. 2010;41(1):124-131.
17. García R, Stea D, Real J, et al. Psychology, participation and environmental policy marking. In García, R. (Coord.), Readings of the Prestige disaster. Contribution from the social sciences Coruña: University of the Coruña. 2013. pp. 132-147.

18. García C, Bustos J. The studies psicological sustainability hydric. Applications to consumer tariff system. Social Science Journal. 2013;139(1):65-90.

19. Basar U. Environmental psychology, urban planning and economics: intersection crossroad \& tangents. Asian Conference Psychology and the Behavior Sciences. Osaka, Japan. 2011.

20. Real J, García R. Dimensions of the concern or environmental n: An approximation the hipermetropy. To environmental Estudy of Psychology. 2001;22(1):87-96.

21. Moser G, Uzzell D. Psychology and the overall challenge of environmental change. International Human Dimensions Programme on Global Environmental Change. 2004;4:1-4.

22. García AR, Real J, Romay J. Temporal and spatial dimensions in the perception of environmental problems: an investigation of the concept of environmental hyperopia. International Journal of Psychology. 2005;40:5-10.

23. Uzzell D, Rice H, Ballantine H, et al. Environmental hyperopia. 13th IAPS Conference, University of Manchester, 13-15 July. 1994.

24. Pol E, Castrechini A. Disrupcion in the education or $\mathrm{n}$ for sustainability? Latin American Journal of psychology. 2013;45(3):335349

25. Rathzel, N, Uzzell D. Mending the beach between labor and nature: environmental engagements of trade unions and the Nort h- South divide. Interface. 2012;4(2):81-100. 